\title{
Paulo Freire e Edgar Morin: duas vozes centenárias da educação
}

\author{
Maria José de Pinho ${ }^{1}$ \\ UFT \\ Fabíola Andrade Pereira ${ }^{2}$ \\ UFNT \\ Maria José da Silva Morais ${ }^{3}$ \\ UFT
}

\section{Resumo}

O presente texto tem como objetivo provocar um diálogo baseado na interlocução epistemológica entre Paulo Freire e Edgar Morin, ambos referência na educação mundial. As duas vozes se cruzarão a partir da análise pautada na categoria do diálogo e oferecerá ao leitor um percurso pelas reflexões e contribuições para a formação integral do sujeito através de uma teia de saberes. Nesse sentido, nossas ideias se unirão nesse exercício de tecer a fim de pensar a educação numa perspectiva dialógica, a partir do pensar complexo, buscamos celebrar o centenário desses patronos da

* Doutora em Educação pela Pontifícia Universidade Católica de São Paulo. Professora dos Programas de Pós-Graduação Mestrado e Doutorado em Ensino de Língua e Literatura e Mestrado e Doutorado em Educação da UFT. Coordenadora do Grupo de Pesquisa em Rede Internacional Investigando Escolas Criativas e Inovadoras. E-mail: mjpgon@mail.uft.edu.br https:// orcid.org 0000.0002.2411.6580

** Doutora em Educação pela Universidade Federal da Paraíba. Professora Adjunta do Curso de Pedagogia da UFNT em Tocantinópolis. É Membro do Núcleo de Pesquisa e Extensão Carolina de Jesus da UFRB na cidade de Amargosa-BA e integrante do PROGERO. É Coordenadora de Área no Programa Institucional de Bolsa de Iniciação à Docência (PIBID). E-mail: fabagnes@mail.uft.edu.br https://orcid.org/0000-0001-5107-9079

*** Doutoranda do Programa de Pós-Graduação em Educação na Amazônia (PGEDA), Universidade Federal do Tocantins (UFT) e Membro do Grupo de Pesquisa em Rede Internacional Investigando Escolas Criativas (RIEC-TO). Professora dos Anos Iniciais do Ensino Fundamental I. E-mail: mel. smassis@gmail.com - _ https://orcid.org/0000-0002-3579-570X 
educação. Assim, inferimos ser indispensável que as instituições de ensino se comprometam com a formação do sujeito na dimensão da abertura, do diálogo, da integração e religação do conhecimento. Esses elementos predispõem práticas educativas transformadoras, além de estabelecer um novo diálogo entre os saberes, as atitudes e a organização do cenário educativo no século XXI.

Palavras-chave: Dialogicidade, saberes interligados, educação formadora e transformadora.

\section{Paulo Freire and Edgar Morin: two centennial voices of education}

\section{Abstract}

This text aims to provoke a dialogue based on the epistemological interlocution between Paulo Freie and Egar Morin, both references in world education. The two voices will cross from the analysis based on the dialogue category and will offer the reader a path through reflections and contributions to the integral formation of the subject through a web of knowledge. In this sense, our ideias will unite in this exercise of weaving in order to think of education in a dialogic perspective, from complex thinking, we seek to celebrate the centenary of these patrons of education. So we infer to be essential that educational institutions commit to the formation of the subject in the dimension of openness, dialogue, integration and reconnection of knowledge. These elements predispose transformative educational practices, in addition to establishing a new dialogue between the knowledge, attitudes and organization of the educational scenario in the XXI century.

Keywords: Dialogic, interconnected knowledge, formative and transformative education

\section{Paulo Freire y Edgar Morin: dos voces centenárias de la educación}

\section{Resumen}

El presente texto tiene como objetivo un diálogo basado en la interlocución epistemológica entre Paulo Freire y Edgar Morin, ambos referencia en la educación mundial. Las dos voces se cruzarán a partir del análisis fundamentado en la categoría del diálogo y ofrecerá al lector un camino por las 
reflexiones y contribuciones para la formación integral del sujeto a través de una red de saberes. En este sentido, nuestras ideas se unirán en este ejercicio de tejer con la finalidad de pensar la educación en una perspectiva dialógica, a partir del pensar complejo, buscamos celebrar el centenario de estos mecenas de la educación. Así, inferimos que es indispensable que las instituciones de enseñanza se comprometan con la formación del sujeto en la dimensión de la abertura, del diálogo, de la integración y reconexión de saberes. Estos elementos predisponen prácticas educativas transformadoras, además de establecer un nuevo diálogo entre los saberes, las actitudes y la organización del escenario educativo en el siglo XXI.

Palabras-clave:Dialogicidad, saberes interconectados, educación formativa y transformadora.

\section{Tecendo saberes a partir de Paulo Freire e Edgar Morin}

Delinear uma análise epistemológica sobre Paulo Freire e Edgar Morin é, sobretudo, nos abrir para o diálogo direto com a amorosidade, a boniteza do ensinar e aprender, a inteireza do ser, a abertura do conhecimento, as incertezas e a percepção de si e do outro. Nesse sentido, compreendemos que os autores defendem as conexões entre os saberes, as teorias e as ciências, em busca de um olhar mais integrado e contextualizado da sociedade e do ser humano.

Para Morin (2003), a interdisciplinaridade também pode significar troca e cooperação, fazendo com que ela possa vir a ser uma coisa orgânica. No entanto, o autor propõe a superação das variadas formas de disciplinaridade, na perspectiva de ecologizar as disciplinas, fomentando saberes que dialogam de forma sistêmica.

O que Morin (2005) nos apresenta são possibilidades para repensarmos como efetivamos o currículo na atualidade, criticando um saber isolado que não se aplica a uma dada realidade prática, tornando-se um saber sem efeito real.

Inferimos que se o currículo não dialoga com a realidade e, portanto, separa os conhecimentos por disciplinas totalmente insuladas, consequentemente, ele pode produzir saberes fragmentados, reducionistas e simplificados. Efetivamente, nas palavras de Morin, haveria um conjunto sistêmico de "cegueiras paradigmáticas" (2011, 
p. 24). Ele reprova o que denomina de inteligência cega sob a qual os processos de disjunção e redução operam e simplificam as complexidades do saber. Nesta visão, sujeito e objeto são coisas distintas, razão e emoção não se abraçam, homem e natureza se opõem.

Morin (2003) discute ser impossível conhecer o todo sem conhecer as partes e conhecer as partes sem conhecer o todo. Para ele, em uma epistemologia sistêmica, oposta à reducionista, o todo é maior que a soma das partes, o que nos implica pensar que tudo pode estar interligado e compor-se da mesma natureza, sendo necessário conhecê-la como um todo integrado. É preciso substituir um pensamento que separa por um que une, pois "todo conhecimento se constitui, ao mesmo tempo, de uma tradução e uma reconstrução, a partir de sinais, signos, símbolos, sob a forma de representações, ideias, teorias, discursos" (MORIN, 2003, p. 23). Interligar e ressignificar são propostas que fazem críticas às pedagogias que escalonam, hierarquizam e não ampliam os significados ao sujeito. Nesse sentido, o pensamento complexo seria a tentativa de ligar os conhecimentos separados, posto que visa integrar os modos de pensar. Trata-se, portanto, da "dialógica do simples e do complexo” (MORIN; SILVA, 1997, p. 84).

A concepção de dialogicidade expressa aqui apresenta a dimensão comunicativa que nos constitui enquanto ser. Assim, vemos dois homens, duas histórias, duas vozes e um caminho que se cruza em prol de um objetivo comum: pensar a educação e compartilhar uma inquietude própria diante da opressão e da marginalização dos sujeitos. Pensar, sobretudo, a boniteza do ato de ensinar, boniteza que deve se instalar na escola e em todos os espaços educativos através da comunicação, pois esta deve servir para construir saberes recheados de sentidos capazes de construir o humano em nós.

De início, poderíamos convidar o leitor ao diálogo que ora conduzimos; a juntar-se a nós nessa interlocução epistemológica a fim de compreender algumas dimensões que se destacam dentro do Pensamento de Freire e Morin, com o intuito de não só celebrar por meio desse manuscrito o centenário do patrono da 
Educação Brasileira, o qual consideramos digno de todas as comemorações, mas que entendemos ser oportuno exercer nosso papel social como professoras e pesquisadoras frente ao seu legado. Assim, compreendemos que a educação, por eles defendida é em sua essência, "um processo ético antes de ser consciência crítica, engajamento político e ação transformadora" (TROMBETTA, 2010 p. 65).

Sob esse olhar, Paulo Freire já demonstrava a importância do educar, pois "ensinar exige compreender que a educação é uma forma de intervenção no mundo" (FREIRE, 1996, p. 98). E intervir requer participação plena do cidadão na sociedade, ou seja, um ser crítico, político e participativo dos contextos locais e globais.

Segundo Freire, não há "ensino sem pesquisa e pesquisa sem ensino. [...] Enquanto ensino continuo buscando, reprocurando. Ensino porque busco, porque indaguei, porque indago e me indago. [...] Pesquiso para conhecer o que ainda não conheço e comunicar ou anunciar a novidade" (1996, p. 29). Esta afirmação nos leva a compreender a importância do rigor metodológico, pois a pesquisa é a fonte de busca da aprendizagem e da criação de novas metodologias. Logo, Freire traz em seu legado a relevância do ensino com fundamentação, e sobretudo que este conhecimento seja para transformação social dos sujeitos.

Como vemos os aportes teóricos que sustentam esta interlocução pautam-se em uma dimensão essencial: o diálogo, tal dimensão nos possibilita compreender a educação numa perspectiva plural, posto que, para Paulo Freire, "não existe a educação, mas educações” (ROMÃO, 2010, p 234), ou seja, há,

formas diferentes de os seres humanos partirem do que são para o que querem ser. Basicamente, as várias "educações” se resumem a duas: uma, que ele chamou de "bancária", que torna as pessoas menos humanas, porque alienadas, dominadas e oprimidas; e outra, libertadora, que faz com que elas deixem de ser o que são, para serem mais conscientes, mais livres e mais humanas. (ROMÃO, 2010, p. 234) 
Entrementes, quando nos reportamos aos escritos de Paulo Freire, vemos que ele nos apresenta uma pedagogia pautada em algumas categorias: a autonomia, a indignação, a liberdade, a esperança e tantas outras, que nutrem sua compreensão sobre a educação e se vislumbram a partir da sua leitura de mundo. Assim, falamos em "Educações", porque ela possui um sentido lógico, ela é comunicativa, permite o diálogo e a escuta, busca libertar, nos mostra que é possível ter esperança e que é permitido a cada um de nós ser quem somos, da forma que somos. Nesse sentido,

\begin{abstract}
Nós podemos dizer que todo o pensamento de Freire é perpassado por um imperativo de respeito à alteridade do outro, seu universo cultural e seu mundo da vida. Sem o respeito à pessoa em sua condição de unicidade, nenhum processo de revolução/humanização é bem sucedido. A assunção de nós mesmos não significa a exclusão dos outros. (TROMBETTA, 2019, p. 64 e 65)
\end{abstract}

Morin, por sua vez, nos exprime que o verdadeiro papel da Educação deve servir para um despertar. Tal despertar (para a arte, para a literatura, para a música, para a filosofia etc) é que dá sentido à vida, a educação, portanto, deve preencher a vida, esse seria seu verdadeiro papel.

Assim, retomamos a afirmação inicial quando mencionamos que essa compreensão de educação deve instalar-se na escola, mas a pergunta é, de que escola falamos? Como a escola pode ajudar nesse processo de "despertar" a que Morin se refere? A partir dessas indagações Gadotti, nos convida a pensar a "escola dos meus sonhos" (2019, p 21), ou dos nossos sonhos. Para ele, "quando a escola fica respondendo a perguntas que ninguém faz, que não mudam a realidade, que não tocam o cotidiano, a aprendizagem se torna algo enfadonho, sem sentido" (2019, p 21). Talvez seja isso que Morin nos alerta: precisamos aprender a estimular a criatividade e a curiosidade de nossas crianças e adolescentes, segundo ele a forma como as disciplinas estão estruturadas só servem para isolar os objetos. A educação por sua vez tem o papel de romper com esse 
formato dualista para mostrar que os saberes possuem correlações, possibilitam mudança social e estimulam o autoconhecimento de forma crítica e criativa.

Nesse aspecto, Torre percebe a "[...] criatividade como valor social e cultural que deveria ser assumida pelas organizações socioculturais e instituições educativas" (2013, p. 145). A criatividade é essencial para haver mudança no contexto educacional, todavia ela necessita ser vista de forma social e não individual. Dessa maneira, a escola enquanto instituição educacional na sociedade contemporânea precisa urgentemente de práticas pedagógicas pautadas na transformação do sujeito, atitudes de responsabilidade e autonomia que busque a construção do conhecimento em sua totalidade (MORAIS, 2015).

A criatividade é um dos elementos fundantes da epistemologia de Freire, pois suas obras são marcadas pelos princípios de liberdade humana, ao criar a "método" de alfabetização de adultos, ele propicia uma oportunidade de que esses sujeitos percebessem a si e o que os cerca. Outro elemento, é a educação libertadora ou problematizadora que "se funda na criatividade e estimula a reflexão e a ação verdadeiras de homens e mulheres sobre a realidade, responde a sua vocação, como seres que não podem autenticar-se fora da busca e da transformação criadora" (FREIRE, 1981, p. 72). Nesse sentido, Pinho e Passos reforçam

a importância de uma educação pautada nos princípios da criatividade, na busca de aportes para uma sociedade do conhecimento em que o homem e a natureza dialeticamente se entrecruzem rompendo as arestas do preconceito, fazendo a vida acontecer em plenitude e beleza, com atitudes transdisciplinares de combate a toda forma de intolerância (PINHO; PASSOS, 2018, p. 23).

Assim, entendemos que para mudar a escola (tal qual conhecemos hoje), primeiro, precisamos sonhá-la, posto que ela é em si, ou pelo menos deveria ser, "um lugar especial". Nessa direção, o primeiro passo seria entendê-la e/ou vê-la como espaço de cons- 
trução da liberdade, e da constituição de alternativas para uma sociedade que precisa cada vez mais dela. Com Freire, aprendemos que a sociedade não precisa de uma escola repetidora, ao contrário, assim como Morin, ele sinaliza a necessidade de prospectarmos uma escola desafiadora. Uma escola que busque sentido para ela mesma, que ouça, que agregue, que acolha, que estimule a criatividade e a capacidade dos nossos estudantes (crianças, jovens, adultos e idosos) a continuarem acreditando que a educação é o caminho possível, portanto, uma escola concebida como espaço de relações sociais e humanas em que a comunicação é possível. Diante desses apontamentos, é importante dizer que "há uma pedagogia indiscutível na materialidade desse espaço” (Freire, 1996, p 50), posto que

A beleza existe em todo lugar. Depende do nosso olhar, da nossa sensibilidade; depende da nossa consciência, do nosso trabalho e do nosso cuidado. A beleza existe porque o ser humano é capaz de sonhar. (GADOTTI, 2011, p 17)

Idealizamos aqui, e o leitor nos permita fazer esse exercício, um ambiente criativo, terno e carregado de amorosidade, um espaço de ensino e aprendizagem, mas também de companheirismo que atenda a necessidade do nosso tempo e que valorize as relações sociais e humanas sadias. Assim, entendemos que uma maneira de prospectar essa escola é tentar entendê-la, é, no entanto, refletir sobre ela, sobre seu processo formativo (sujeito) e sua prática. Eis aqui o inédito viável:

[...] uma das bonitezas do anúncio profético está em que não anuncia o que virá necessariamente, mas o que pode vir, ou não. Na real profecia, o futuro não é inexorável, é problemático. Há diferentes possibilidades de futuro [...] contra qualquer tipo de fatalismo, o discurso profético insiste no direito que tem o ser humano de comparecer à História não apenas como seu objeto, mas também como sujeito. O ser humano é, naturalmente, um ser da intervenção no mundo à razão de que faz a História. Nela, por isso mesmo, deve deixar suas marcas de sujeito e não pegadas de puro objeto. (FREIRE, 2000, p. 119) 


\title{
Para Redin,
}

Esta boniteza pode se instalar na educação e na escola. Se nelas se instalar a tristeza esta poderá deteriorar a alegria de viver. Viver plenamente a alegria na escola significa mudá-la, significa lutar para incrementar, melhorar, aprofundar a mudança. (REDIN, 2010, p. 110)

Ainda segundo este autor, o texto a seguir sintetiza o pensamento de Paulo Freire quando faz referência a essa escola. Vejamos:

\author{
Escola é... \\ o lugar onde se faz amigos, \\ não se trata só de prédios, salas, quadros, \\ programas, horários, conceitos... \\ Escola é, sobretudo, gente, \\ gente que trabalha, que estuda, \\ que se alegra, se conhece, se estima. \\ O diretor é gente, \\ O coordenador é gente, o professor é gente, \\ o aluno é gente, \\ cada funcionário é gente. \\ E a escola será cada vez melhor \\ na medida que cada um \\ se comporte como colega, amigo, irmão.
}

Nada de "ilha cercada de gente por todos os lados".

Nada de conviver com pessoas e depois descobrir

que não tem amizade a ninguém,

nada de ser como tijolo que forma a parede,

indiferente, frio, só.

Importante na escola não é só estudar, não é só trabalhar,

é também criar laços de amizade,

é criar ambiente de camaradagem,

é conviver, é se "amarrar nela"!

Ora, é lógico...

numa escola assim vai ser fácil

estudar, trabalhar, crescer,

fazer amigos, educar-se,

ser feliz. (REDIN, 2010, p. 110) 
$\mathrm{Na}$ esteira dessa abordagem, entendemos que a dialogicidade, essência da pedagogia freiriana, constitui a mola propulsora de todo processo, já que ela incentiva o sujeito a dizer a sua palavra. Assim, o princípio potencializador do diálogo é, portanto, um instrumento importante no processo de comunicação, pois nos permite anunciar e denunciar, como podemos ver nesta passagem de Freire: "o diálogo não é um produto histórico, é a própria historicização" (FREIRE. 1981, p.10).

Assim como Paulo Freire, o pensador Edgar Morin coloca a dialogicidade como um aspecto indispensável para o exercício da cidadania e a prática da justiça, uma vez que propiciam mudanças ao ser humano. Esta dinâmica nos remete ao pensamento de Heráclito, ao afirmar que "não se mergulha duas vezes no mesmo rio, tudo flui" (apud MORIN, 2020, p. 35).

É a partir desta analogia que Morin nos convida a perceber a mudança diária do ser, essa transformação e dialogicidade são indispensáveis para vivermos com as incertezas e complexidade do universo. Nesse sentido, nos proporciona os sete saberes fundamentais para uma educação integral. Sendo eles: o conhecimento, o conhecimento pertinente, a condição humana, a compreensão humana, a incerteza, a era planetária e a antropoética.

Para Morin, o conhecimento perpassa dois caminhos, o primeiro pode ser perigoso, pois pode induzir-nos a erros, à ilusão e à cegueira. O segundo é o conhecimento na busca do novo, da integração e do diálogo. Com esse olhar, o autor explicita a importância de "[...] ensinar que todo conhecimento é tradução e reconstrução" (2009, p. 82).

Diante desse contexto, o filósofo apresenta que o conhecimento pertinente é aquele capaz de realizar conexões entre as partes e a totalidade, os objetos em seu contexto local e global. Essa articulação, dispõem em

[...] organizar os conhecimentos e assim reconhecer e conhecer os problemas do mundo, é necessário a reforma do pensamento. Entretanto, essa reforma é paradigmática e, não, pragmática: é a questão fundamental da 
educação, já que se refere à nossa aptidão para organizar o conhecimento. (MORIN, 2002, p. 35)

Nesse aspecto, o autor menciona a reforma do pensamento como uma via fundante da organização do conhecimento, pois dispõe religá-lo com outras vias multidimensionais e ecossistêmicas.

Diante disso, a condição humana para Morin, é primordial para compreender a nossa identidade em sua complexidade e totalidade. Ou seja, problematizar "quem somos, afinal?" (2009, p. 89) Os seres humanos têm "[...] uma natureza biológica, uma natureza social, uma natureza individual" (2009, p. 89). A dimensão do sujeito a partir dessa tríade contribui com a integralidade e multiplicidade do ser. Esses três eixos supracitados pelo autor nos remetem à apreensão da singularidade humana e à interdependência do universo, pois o ser humano é composto de razão, emoção e sonhos. Essas polaridades são partes do sujeito e carecem de ser consideradas pela ciência para o entendimento de si e de tudo que há no universo (MORIN, 2009).

Para Morin, a compreensão humana "em nenhum lugar é ensinado a compreendermos uns aos outros” (2009, p. 92). Esse aspecto, implica um esforço tanto de empatia quanto de projeção. $\mathrm{O}$ autor ainda sinaliza que a sociedade sofre de uma ausência de compreensão, devido às diferentes culturas e até mesmo modos de viver.

Em virtude disso, é indispensável olhar para o interior e ver nossos comportamentos egocêntricos e individualistas. É a partir da percepção "melhor de si mesmo, [que] compreende-se melhor o outro" (MORIN, 2009, p. 95). Dessa maneira, percebe-se que a compreensão humana é uma autoanálise, que observada de forma isolada do todo do sujeito, pois carece de ser pensada em sua multirreferencialidade para que de fato aconteça o progresso humano na contemporaneidade. Diante desse contexto, entendemos que as instituições de ensino são espaços propícios para a compreensão das dimensões individuais e coletivas.

A incerteza é um saber pertinente e essencial à vida e tudo que faz parte dela. No entanto, durante séculos a ciência clássica enfati- 
zou a certeza, mas sabe-se que a cientificidade teve que negociar com o incerto em busca de nova forma de pensar e conhecer o mundo (MORIN, 2009). Além disso, cabe pontuar a relação desse conhecimento com o que a humanidade está vivendo, a incerteza diária, em que a pandemia é um exemplo de que nada é certo e óbvio.

Portanto, "a inquisição da incerteza é uma das maiores conquistas da consciência, porque a aventura humana, desde seu começo, sempre foi desconhecida" (MORIN, 2009, p. 99). Logo, esse saber necessita reverberar nas instituições de ensino e na sociedade para que se tenha condições de enfrentar o inesperado, isto implica primeiramente "consciência do risco e do acaso". Bem como ser capaz de transformar o comportamento humano em novos conhecimentos e esses serem para o bem individual, social e global. Cabe destacar, que

[...] essa visão interligadora não isola e nem mesmo descarta a ciência - ao contrário, apresenta a sua relevância e complementa com novos fatores e seres que agrega na construção de conhecimentos e nas diferentes formas de ver o mundo, ou seja, na forma de viver e ser nesta dimensão planetária. (SOUZA, 2019, p. 48)

Para tanto, a era planetária, requer uma política multidimensional, compromisso ético, responsabilidade individual e coletiva com e no planeta (MORIN, 2009).

$\mathrm{Na}$ esteira dessa abordagem, o autor nos brinda com o saber da antropoética, resgatando a história de nossa espécie, de nossos ancestrais e a dimensão do cuidado do ser humano e do planeta. Ele propicia a consciência antropológica que religa e reconhece a unidade de tudo, "pois não se pode reformar a educação sem, previamente, ter reformado os espíritos e vice-versa” (MORIN, 2009, p. 104).

Inferimos, que os saberes elucidados por Morin, são contribuições valorosas para educação, já que estes conhecimentos implicam uma mudança nos currículos e nas práticas pedagógicas das instituições educativas. Dessa forma, parece-nos urgente uma educação que prima pelo conhecimento aberto, flexível, interligador e 
preocupada com as dimensões planetárias, sobretudo que esta seja a partir da vida e para a vida. Assim, contribuiremos com o legado de Morin, que dedica a maior parte da sua vida debruçado a compreender os problemas do mundo contemporâneo.

Freire, por sua vez, nos alerta para que sejamos sujeitos construtores de conhecimento e liberdade e refutamos qualquer opressão, marginalização e silenciamento, portanto, cabe a nós uma educação problematizadora, dialógica, crítica e criativa.

\section{Considerações finais}

O presente texto buscou tecer uma epistemologia de Paulo Freire e Edgar Morin, vozes centenárias da educação mundial. Aqui buscamos caminhar pelas teias centrais desses seres que dialogam com uma educação de amorosidade, dialogicidade, boniteza, complexidade e utopia. Sobretudo, nos fazem repensar o nosso compromisso com um conhecimento que integra, humaniza, sensibiliza, ou seja, que possibilita a criação, autonomia e a transformação social do ser humano.

Diante do exposto, é possível depreender que a formação do sujeito perpassa todos os âmbitos do contexto educativo. Nesse sentido, esses centenários são sujeitos que nos deixam conhecimentos que perpassam as instituições educativas, pois valorizam os diversos saberes. E ainda reforçam a importância da formação pautada na articulação, na religação, na valorização do sujeito que pensa, transforma e recria continuamente seus contextos.

\section{Referências}

FREIRE, Paulo. Pedagogia da indignação: carta pedagógica e outros escritos. São Paulo: UNESP, 2000.

FREIRE, Paulo. Pedagogia da autonomia: Saberes necessários à prática educativa. São Paulo: Paz e Terra, 1996.

FREIRE, Paulo. Pedagogia do oprimido. 9. ed. Rio de Janeiro: Paz e Terra, 1981. 
GADOTTI, Moacir. A escola dos meus sonhos. São Paulo: Instituto Paulo Freire, 2019.

GADOTTI, Moacir. Boniteza de um sonho: ensinar e aprender com sentido, $2^{\mathrm{a}}$ Ed. São Paulo: Instituto Paulo Freire, 2011. Educação Cidadã.

MORIN, Edgar, SILVA, Juremir Machado da. Edgar Morin, o mestre da complexidade: Entrevista de Edgar Morin a Juremir Machado da Silva. Estudos Leopoldenses: série educação, Vol. 1, nº 1, São Leopoldo, p. 81-92, 1997.

MORIN, E. Os sete saberes necessários à educação do futuro. 3. ed. São Paulo: Cortez, 2003.

MORIN, E. O Método 6: ética. Porto Alegre: Sulina, 2005.

MORIN, Edgar. Introdução ao pensamento complexo. Porto Alegre: Sulina, 2011.

MORIN, Edgar. Meus filósofos. 2. ed. Porto Alegre: Sulina, 2020. Tradução de Edgar de Assis Carvalho e Mariza Perassi Bosco.

MORIN, E. Os Sete Saberes necessários à Educação do Futuro. 5 ed. São Paulo; Brasília: Cortez; UNESCO, 2002. Tradução de Catarina Eleonora F. da Silva e Jeanne Sawaya.

MORIN, Edgar; ALMEIDA, Maria Conceição de; CARVALHO, Edgard de Assis (orgs.). Educação e complexidade: os sete saberes necessários. São Paulo: Cortez, 2009.

MORAIS, Maria José da Silva. Criatividade na formação continuada de professores do ensino fundamental: um desafio na contemporaneidade. 2015. 181 f. Dissertação (Mestrado) - Curso de Educação, Programa de Pós-Graduação em Educação, Universidade Federal do Tocantins, Palmas, 2015.

PINHO, Maria José de; PASSOS, Vânia Maria de Araújo. COMPLEXIDADE, ECOFORMAÇÃO E TRANDISCIPLINARIDADE: por uma formação docente sem fronteiras teóricas. Revista Observatório, v. 4, n. 2, p. 433-457, 1 abr. 2018.

REDIN, Euclides. Boniteza. In: STRECK, Danilo R.; REDIN, Euclides; ZITKOSKI, Jaime José (Orgs.). Dicionário Paulo Freire. $2^{\mathrm{a}}$ ed. Belo Horizonte: Autêntica, 2010. p. 65. 
Romão. José Eustáquio. Educação. In: STRECK, Danilo R.; REDIN, Euclides; ZITKOSKI, Jaime José (Orgs.). Dicionário Paulo Freire. $2^{\mathrm{a}}$ ed. Belo Horizonte: Autêntica, 2010, p. 234.

SOUZA, Kênia Paulino de Queiroz. Complexidade e ecoformação: um olhar epistemológico na dimensão socioambiental do programa ciências do ambiente. 2019. 156 f. Tese (Doutorado) - Curso de Ciências do Ambiente, Programa de Pós-Graduação em Ciências do Ambiente, Universidade Federal do Tocantins, Palmas, 2019.

TORRE, Saturnino de la. Movimento de escolas criativas: fazendo parte da história de formação e transformação. In: ZWIEREWICZ, M. Criatividade e inovação no ensino superior: Experiências latino-americanas e europeias em foco. Florianópolis: Nova Letra, 2013. p. 141 -164.

TROMBETTA, Sérgio. Alteridade. In: STRECK, Danilo R.; REDIN, Euclides; ZITKOSKI, Jaime José (Orgs.). Dicionário Paulo Freire. $2^{\mathrm{a}}$ ed. Belo Horizonte: Autêntica, 2010, p. 64 -65. 